\title{
Spatial synchrony and temporal dynamics of juvenile red drum Sciaenops ocellatus populations in South Carolina, USA
}

\author{
Stephen A. Arnott ${ }^{1, *}$, William A Roumillat ${ }^{1}$, John A. Archambault ${ }^{1}$, \\ Charles A. Wenner ${ }^{1}$, Joy I. Gerhard ${ }^{1,2}$, Tanya L. Darden ${ }^{1}$, Michael R. Denson ${ }^{1}$ \\ ${ }^{1}$ Marine Resources Research Institute, South Carolina Department of Natural Resources, Charleston, \\ South Carolina, 29412, USA \\ ${ }^{2}$ Grice Marine Laboratory, College of Charleston, Charleston, South Carolina, 29412, USA
}

\begin{abstract}
Across a species' range, the population dynamics of some areas may express spatial synchrony (i.e. they fluctuate with one another), whereas other areas may express no synchrony (they fluctuate independently). The degree of synchrony and spatial extent of synchrony are important considerations when assessing the population as a whole. We examined these aspects in red drum Sciaenops ocellatus along the coast of South Carolina using long-term survey data of juvenile abundance in estuarine areas separated by up to $\sim 200 \mathrm{~km}$. Synchrony of year class strength was detected among areas, but the degree of synchrony declined significantly with distance. By comparison, genetic segregation along the coast was either weak or undetectable (based on allele frequencies at 8 microsatellite loci), although it depended on the year class $(2004,2005$ or 2007) of fish that was tested. By standardizing juvenile abundance data across estuaries and survey types, a single, regionwide juvenile time series was generated that covered the 1985-2007 year classes. The juvenile time series correlated significantly with the year class composition of the present-day adult population, which was determined using otoliths collected by a separate survey operating in deeper adult habitats. Future work integrating data across even broader spatial scales would assist in the understanding of large-scale ecological processes that control fluctuations in red drum populations, and would provide useful information for fishery managers.
\end{abstract}

KEY WORDS: Sciaenops ocellatus - Red drum - Synchrony · Population dynamics · Recruitment · Genetics $\cdot$ Microsatellites $\cdot$ South Carolina

\section{INTRODUCTION}

The overall temporal dynamics of a population is the sum of many localized population processes that occur in different areas across a species' range. These localized changes can operate with varying degrees of spatial synchrony, which is defined as the co-variation in population density fluctuations (Bjørnstad et al. 1999). Spatial synchrony is of general ecological importance because it affects the likelihood of a species' extinction (Heino et al. 1997, Liebhold et al. 2004) and raises fundamental questions about the forces that control synchrony. It is also important in fisheries management because population assessments that encompass a large region might be locally inaccurate, or inappropriate, if different areas fluctuate independently of one another (i.e. without synchrony), and because synchrony affects population stability, which has associated economic effects on societies that harvest the population (Schindler et al. 2010).

Simulation models show that at least 3 major mechanisms can induce spatial synchrony among populations. These include: the dispersal of individuals; the influence of spatially autocorrelated densityindependent factors (e.g. climate); and the influence of density-dependent factors, which themselves have 
spatial synchrony or are mobile (e.g. competition or predation) (Ranta et al. 1995, 1997, Hudson \& Cattadori 1999, Liebhold et al. 2004). Distinguishing between these factors is difficult and their combined effects may lead to non-intuitive responses (Ranta et al. 1995, Hudson \& Cattadori 1999).

Large-scale spatial autocorrelations of density-independent environmental conditions have been widely studied as a mechanism that can lead to spatial synchrony. The underlying theory, which was first formulated by Moran in his study of Canadian lynx and hare population cycles (Moran 1953a,b), predicts that local populations with similar density-dependent structures should become synchronized under the influence of a spatially autocorrelated, density-independent factor (Royama 1992, Hudson \& Cattadori 1999). This theory is relevant to fisheries because environmental conditions are well known to have major effects on fish population dynamics. In particular, the conditions experienced by the early life stages are critical in determining recruitment success because mortality rates are extremely high. Consequently, any environmental factor that modifies early mortality can have a disproportionate effect on the number that eventually recruit to a fishery (Hjort 1914, Cushing 1985, Bailey \& Houde 1989).

Environmental conditions are often spatially autocorrelated across wide areas (e.g. warmer or colder than average years tend to affect whole regions), so synchrony in recruitment can arise across geographically separated populations, even if dispersal barriers exist between them (Phelps et al. 2008). For example, large-scale processes such as the El Niño-Southern Oscillation and the North Atlantic Oscillation have particularly widespread environmental effects that drive region-wide population events in many organisms, including fish (Stenseth et al. 2002, Allen et al. 2008).

Myers et al. (1997) examined the spatial extent of recruitment synchrony in a variety of fishes, including 11 marine, 5 anadromous and 3 freshwater species. Their main finding was that synchrony is geographically more widespread among marine species $(\sim 500 \mathrm{~km})$ than among freshwater species $(\sim 50 \mathrm{~km})$, with anadromous species lying in between. The wider extent of synchrony among marine species may be because marine habitats are environmentally more homogenous (i.e. the Moran effect), or because they offer greater opportunity for dispersal between areas.

Fishery assessments typically depend on recruitment indices as model input values for determining the status of a population. However, without any knowledge of the extent of spatial synchrony, it is unclear how meaningful any single measure of recruitment is with respect to the population that is being assessed.
In the present study, we examined the population dynamics and spatial synchrony of juvenile red drum Sciaenops ocellatus along the coast of South Carolina, USA (western North Atlantic). The full range of the species extends from Massachusetts, USA, in the Atlantic (Lux \& Mahoney 1969) to Veracruz, Mexico, in the Gulf of Mexico (Mercer 1984). Red drum typically inhabit estuarine and coastal marsh areas as juveniles, and nearshore shelf waters as adults (i.e. $\sim 5$ yr and older) (Pearson 1929). In South Carolina, eggs are spawned during August to November in areas such as deepened hollows near the mouths of estuaries (Wenner 2000), yielding larvae that settle in estuarine creeks and marsh front (Peters \& McMichael 1987, Stunz et al. 2002). Adult fish can exceed $1 \mathrm{~m}$ in length and in North Carolina they can live for more than $60 \mathrm{yr}$, although the maximum life span is 35 to $40 \mathrm{yr}$ in areas further south, including South Carolina (Ross et al. 1995, Murphy \& Crabtree 2001, SEDAR 2009b).

Red drum provide important recreational and commercial fisheries in many US coastal areas, although commercial exploitation has been banned in South Carolina since 1987. In some areas, including South Carolina (Smith et al. 1997, Collins et al. 2002, Jenkins et al. 2004), stocking of red drum has been used for experimental or stock enhancement purposes. Population assessments are performed by the Atlantic States Marine Fisheries Commission, which subdivides red drum into northern Atlantic (Massachusetts to North Carolina), southern Atlantic (South Carolina to SE Florida) and Gulf of Mexico (SW Florida to Texas) management units.

Since 1986, the South Carolina Department of Natural Resources (SCDNR) has performed several fishery-independent surveys that catch red drum in estuarine and nearshore habitats. In the present study, we used data from these surveys to examine the temporal and spatial dynamics of juvenile red drum populations in South Carolina, concentrating only on wildspawned (i.e. not stocked) fish. First, we assessed the catches of 4 separate juvenile surveys that used different gears and were conducted over different (but overlapping) years to evaluate whether they show similar dynamics in relative year class abundance. Second, we quantified the spatial scale of juvenile population synchrony among areas separated by up to $219 \mathrm{~km}$ along the South Carolina coastline, and tested whether synchrony was related to genetic segregation among habitats. Third, we devised a region-wide juvenile time-series that spanned 23 yr by standardizing and concatenating data across all 4 juvenile surveys. Finally, we tested whether the region-wide juvenile time series was related with year class composition of the current adult population. 


\section{MATERIALS AND METHODS}

Red drum catch data were used from 4 juvenile surveys and one adult survey, all performed by the SCDNR along the South Carolina coastline (Fig. 1). Every captured red drum was counted and measured to the nearest millimeter for total length (TL). Where we have assigned age classes to red drum (see below), we used a 1 Jan age transition date (i.e. age-0 from the

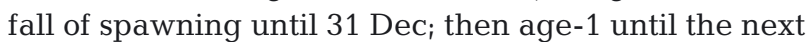
31 Dec, etc.; SEDAR 2009b). The data used from each survey are described below, and details of the methods used for catching red drum by each survey are described in the supplement (see www.int-res.com/ articles/suppl/m415p221_supp.pdf).

Juvenile surveys. Rotenone survey (1986-1994): The rotenone survey was conducted from June 1986 to July 1994. Fish were collected from a total of 11 different tidal creeks that drained intertidal marsh flats. Most sites were in mid- to upper-estuarine areas (mean salinity $=16$ psu across all sets analyzed).

We examined age- 0 and age- 1 red drum abundance in the rotenone survey. Age- 0 data came from 81 sets made at 9 sites during September to December from 1986 to 1991, except in 1988 when no sets were made. Age-1 data came from 157 sets taken at 11 sites during March to July from 1986 to 1994 (Table 1).

Stop net survey (1986-1996): We used stop net data collected between July 1986 and September 1996 from

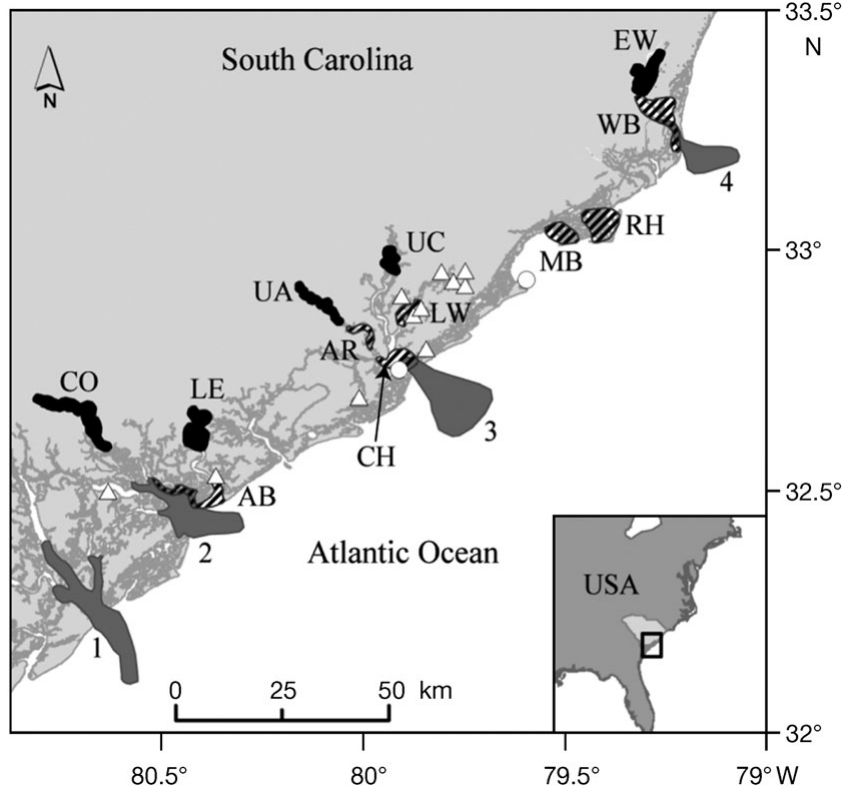

Fig. 1. Sciaenops ocellatus survey locations. Areas surveyed using rotenone (triangles), stop nets (circles), trammel nets (hatched areas), electrofishing (black areas) and adult longlines (gray areas).Trammel net strata: AB: ACE Basin; AR: Ashley River; CH: Charleston Harbor; LW: Lower Wando River; MB: Muddy Bay and Bulls Harbor; RH: Romain Harbor; WB: Winyah Bay. Electrofishing strata: CO: Combahee River; EW: Waccamaw River; LE: Edisto River; UA: Ashley River; UC; Cooper River. Adult long-line strata: 1: Port Royal Sound;

2: St. Helena Sound; 3: Charleston Harbor; 4: Winyah Bay

Table 1. Sciaenops ocellatus surveys. Summary of data used for deriving time series of juvenile red drum in each of the survey strata. On each sampling occasion, sampling sites were either at fixed stations (f) or drawn from a list of potential sites either at random (r) or non-randomly (nr). Age class: age in years. Sites: total number of sites that were sampled across all years. Year class: year of birth. Sets: total number of sets analyzed. No.: total number of target-aged (i.e. belonging to age class of interest) red drum caught. See Fig. 1 for locations and definitions of strata

\begin{tabular}{|c|c|c|c|c|c|c|c|c|c|}
\hline Gear & $\begin{array}{l}\text { Age class } \\
\text { (yr) }\end{array}$ & $\begin{array}{l}\text { Stratum } \\
\text { name }\end{array}$ & Sites & & $\begin{array}{c}\text { Year } \\
\text { classes }\end{array}$ & $\begin{array}{c}\text { Survey } \\
\text { years }\end{array}$ & $\begin{array}{l}\text { Survey } \\
\text { months }\end{array}$ & Sets & No. \\
\hline Rotenone & 0 & Rotenone & 9 & (nr) & $1986-87,1989-91$ & $1986-87,1989-91$ & Sep-Dec & 81 & 349 \\
\hline Rotenone & 1 & Rotenone & 12 & (nr) & 1985-93 & 1986-94 & Mar-Jul & 157 & 1315 \\
\hline Stop net & 1 & 0001 & 1 & (f) & $1985-95$ & $1986-96$ & Jul-Dec & 53 & 3122 \\
\hline Stop net & 1 & 0270 & 1 & (f) & $1988-92,1995$ & $1989-93,1996$ & Jul-Dec & 12 & 433 \\
\hline \multirow[t]{7}{*}{ Trammel } & 1 & $\mathrm{AB}$ & 29 & $(\mathrm{r})$ & $1993-2007$ & $1994-2008$ & Jul-Dec & 947 & 1933 \\
\hline & 1 & $\mathrm{AR}$ & 31 & $(\mathrm{r})$ & $1991-2007$ & $1992-2008$ & Jul-Dec & 1088 & 673 \\
\hline & 1 & $\mathrm{CH}$ & 27 & $(\mathrm{r})$ & $1990-2007$ & $1991-2008$ & Jul-Dec & 922 & 1715 \\
\hline & 1 & LW & 30 & $(\mathrm{r})$ & $1990-2007$ & $1991-2008$ & Jul-Dec & 995 & 2038 \\
\hline & 1 & MB & 26 & $(\mathrm{r})$ & $1996-2007$ & $1997-2008$ & Jul-Dec & 752 & 1815 \\
\hline & 1 & RH & 30 & $(\mathrm{r})$ & $1996-2007$ & $1997-2008$ & Jul-Dec & 763 & 1442 \\
\hline & 1 & WB & 31 & $(\mathrm{r})$ & $2001-07$ & $2002-08$ & Jul-Dec & 346 & 439 \\
\hline \multirow[t]{5}{*}{ Electro } & 1 & $\mathrm{CO}$ & 150 & $(\mathrm{r})$ & $2000-07$ & 2001-08 & Jul-Dec & 239 & 87 \\
\hline & 1 & EW & 54 & (r) & $2002-07$ & 2003-08 & Jul-Dec & 136 & 139 \\
\hline & 1 & LE & 81 & $(\mathrm{r})$ & $2000-07$ & 2001-08 & Jul-Dec & 219 & 83 \\
\hline & 1 & UA & 77 & $(\mathrm{r})$ & $2000-07$ & 2001-08 & Jul-Dec & 258 & 162 \\
\hline & 1 & UC & 62 & $(\mathrm{r})$ & $2000-07$ & 2001-08 & Jul-Dec & 266 & 195 \\
\hline Total & & & 651 & & & & & 7234 & 15940 \\
\hline
\end{tabular}


2 lower estuarine sites (Site 0001, Grice Cove in Charleston Harbor, $32.7466^{\circ} \mathrm{N}, 79.8978^{\circ} \mathrm{W}$; Site 0270, Bull Island, $\left.32.9308^{\circ} \mathrm{N}, 79.5766^{\circ} \mathrm{W}\right)$. Mean salinity across all sets analyzed was 22.5 psu at Site 0001 and $31.8 \mathrm{psu}$ at Site 0270 .

We examined age-1 red drum abundance in sets taken during July to December. For Site 0001, this gave a total of 53 sets ( 5 to 7 sets per year in 1986 to 1993; 3 sets in 1994; 1 set each for 1995 and 1996). For Site 0270 , a total of 12 sets were analyzed ( 1 to 3 sets per year during 1989 to 1993 and 1996).

Trammel net survey (1991-present): The trammel net survey began during 1991 in 2 strata $(\mathrm{CH}$ and $\mathrm{LW}$; for definitions of strata abbreviations, see Fig. 1) within the Charleston Harbor system (Fig. 1). Additional strata were added to the survey over time (see Table 1). All strata ( 7 in total) were in mid- or lowerestuary marsh areas (Fig. 1). Mean salinity in each stratum (during all sets analyzed) ranged between 17.4 psu (WB) and 32.1 psu (RH).

We examined age-1 red drum abundance using sets taken in July to December, which gave a total of between 346 and 1088 sets per stratum (Table 1). From 1991 to 1994 , the mean number of sets per month in each stratum varied between $3.8(\mathrm{CH})$ and $8.7(\mathrm{AB})$. From 1995 onwards, the mean number ranged from 8.2 (WB) to 11.4 (AR).

Electrofishing survey (2001-present): The electrofishing survey began in 2001 in 4 strata and expanded into a fifth stratum in 2003 (Table 1). All were located in upper-estuary, oligohaline areas (Fig. 1), with mean salinities per stratum (all sets analyzed) of $2.5 \mathrm{psu}(\mathrm{CO})$ to $3.5 \mathrm{psu}$ (UC).

We examined age-1 red drum catch data from sets made during July to December. The mean number of sets per month varied between 3.8 (EW) and 5.5 (UC) in each stratum. The total number of sets analyzed per stratum across all years varied between 136 and 236 (Table 1).

Adult red drum. Long-line survey: In 2007 and 2008, adult red drum were collected from 4 sampling strata (Fig. 1) using bottom long-lines. Every third captured red drum was sacrificed and its sagittal otoliths were extracted, cleaned and stored dry for age determination.

Year class composition of adults: The age class (age in years) and year class (year of birth) of each adult were determined from a transverse section ( 0.3 to 0.4 $\mathrm{mm}$ ) cut through the nucleus of its left sagittal otolith using a low-speed saw (Buehler). Sections were mounted on glass slides and images were captured through a microscope (Nikon SMZ-U) using a digital color camera (Scion CFW-1310C). Annuli were counted by 2 independent readers and checked for agreement. Year class was assigned assuming 1 annulus is deposited per year, with the first being deposited during spring at age-2 (Wenner et al. 1990, Ross et al. 1995).

Of the 101 otoliths examined, 52 came from the northern part of South Carolina (all from Winyah Bay) and 47 came from the southern part (18 from Charleston Harbor, 8 from St. Helena Sound and 21 from Port Royal Sound; Fig. 1). Chi-square tests were used to test whether any gross regional (northern vs. southern) or temporal (2007 vs. 2008 samples) differences existed in year class composition. For this, it was necessary to pool data from neighboring year classes into bins sufficient to give expected observations of 5 or more (number of year classes per bin ranged between 2 and 8).

Genetics. A proportion of the juvenile red drum caught in the trammel and electrofishing surveys were genotyped in order to distinguish stocked fish from wild-spawned fish, and to examine genetic distances between fish from different survey strata. Fish caught in the adult survey were also genotyped to confirm that they were wild-spawned.

Fin clips $\left(\sim 25 \mathrm{~mm}^{2}\right)$ were collected from surveycaught juveniles belonging to the 1999 year class or later (n > 1500 fin clips, or $\sim 19 \%$ of all age-1 fish caught). They were also collected from all long-lined adults and parents of stocked fish. Tissue was preserved in $1 \%$ sarcosyl, $8 \mathrm{M}$ urea, $20 \mathrm{mM}$ sodium phosphate and 1 mM EDTA (pH 6.8). DNA was extracted using a SprintPrep metal bead isolation protocol (Agencourt) and stored in $10 \mathrm{mM}$ tris and $1 \mathrm{mM}$ EDTA. All samples were genotyped at 8 microsatellite loci using standard PCR methods optimized for multiplexed groups of either 2 or 3 primers (further PCR and primer details are given in the supplement).

Juveniles were categorized as either stocked or wildspawned fish by comparing their genotypes against the parents of the stocked fish. The parentage analysis was performed using PROBMAX 1.3 software (Danzmann 1997) implemented with the criteria and testing procedures described by Robbins et al. (2008).

To determine the genetic distances between wildspawned juveniles from different sampling strata, allele frequencies were calculated using the Excel Microsatellite Toolkit (http://animalgenomics.ucd.ie/sdepark/ ms-toolkit/). Pairwise genetic distances between strata were calculated using the GenDist program of the PHYLIP v3.69 package (http://evolution.genetics. washington.edu/phylip.html). All alleles were included at each locus and estimates were obtained for Nei's genetic distance (Nei 1972), Cavalli-Sforza and Edward's (C-S) chord distance (Cavalli-Sforza \& Edwards 1967) and Reynolds, Weir and Cockerham's (RWC) genetic distance (Reynolds et al. 1983). Nei's distance assumes that new mutations occur by the infinite isoalleles neutral mutation model (Kimura \& Crow 1964), whereas the 
latter 2 assume only genetic drift. Genetic distances were calculated separately for the 2004, 2005 and 2007 year classes. For the 2005 year class, fish $(n=330)$ were analyzed from all strata (maximum geographic distance between strata $=219 \mathrm{~km})$. For the 2004 and 2007 year classes, fish ( $\mathrm{n}=461$ and 324, respectively) were analyzed from all strata except $\mathrm{AB}, \mathrm{CO}$ and LE (maximum geographic distance $=139 \mathrm{~km}$ ).

Time series of juvenile abundance. Catch per unit effort: Our analyses of juvenile red drum catch per unit effort (CPUE) only considered fish that were wildspawned. The effects of stocking were excluded by genetically identifying stocked fish (see above) or, in some cases, by external tags applied to stocked fish. In year classes and strata with stocked fish, estimates of wildspawned red drum abundance included an adjustment to account for the proportion of stocked fish caught.

A total of 16 time series for juvenile abundance were calculated, including: an age-0 rotenone time series; an age- 1 rotenone time series; 2 age-1 stop net time

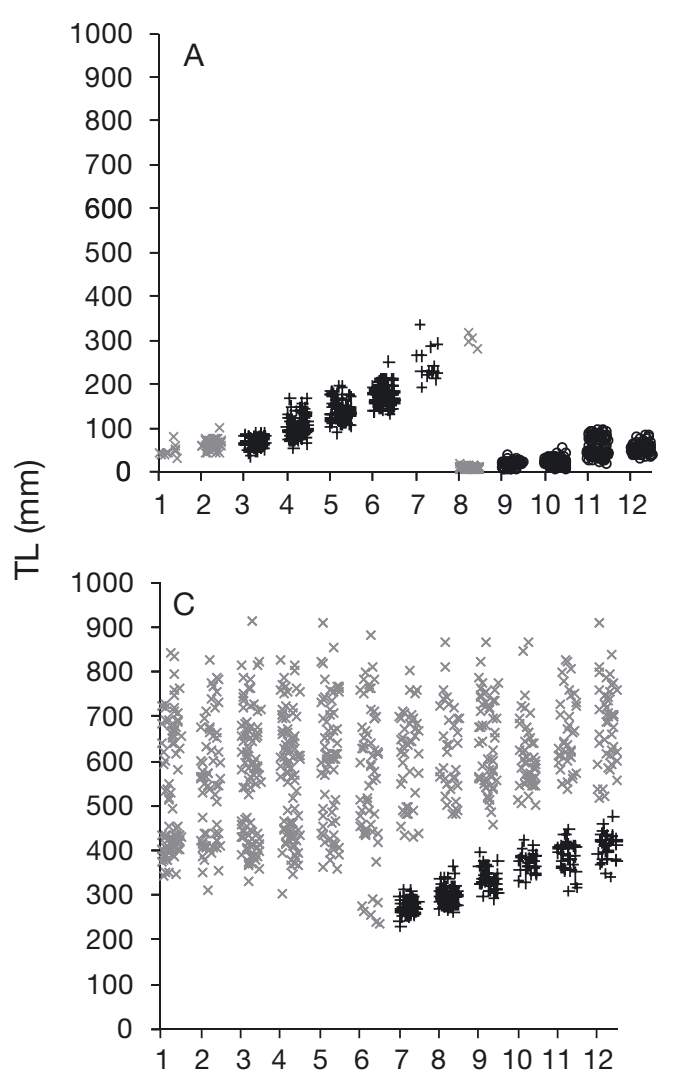

series; 7 age-1 trammel time series; and 5 age- 1 electrofishing time series (Table 1). Fish ages were clearly discernable due to distinct length cohorts for the months and ages of interest (Fig. 2).

The method used for calculating each time series was governed by the catch frequency distribution of each gear type (Fig. 3). In the stop net survey, sets with a zero catch were rare (3.1\% of sets) and square-root transformed catch numbers (Zar 1996) were used for evaluating CPUE because these data were normally distributed (Anderson-Darling test, $p=0.28$; raw catch and log-transformed catch data were not normally distributed, $\mathrm{p} \leq 0.005)$. The mean CPUE for each stop net year class was calculated using the general linear model function of Minitab 15 (www.minitab. com), with year class and month entered as fixed factors. Least square means were back-transformed to generate the stop net time series.

Among the remaining juvenile surveys, zero catch data were more common (23.5 to $63.3 \%$ of sets; Fig. 3 )
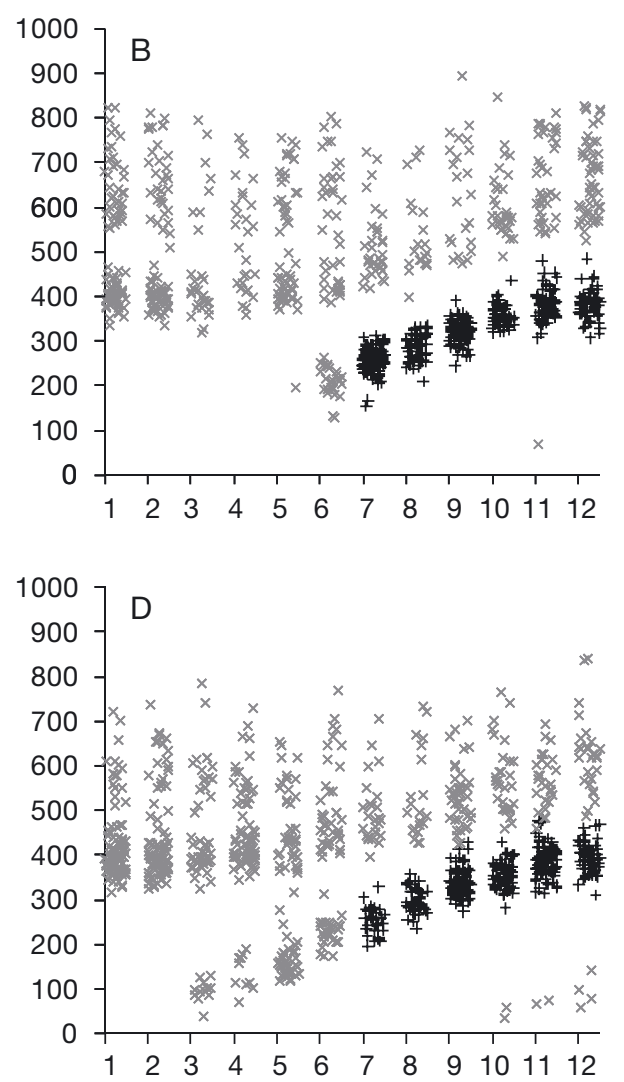

Month

Fig. 2. Sciaenops ocellatus. Total length (TL) measurements of individual red drum caught in the (A) rotenone, (B) stop net, (C) trammel net and (D) electrofishing surveys. Each panel shows 1000 individuals, randomly selected from the database for each gear type. Black circles: fish used for calculating the age-0 time series (rotenone survey only); black pluses: fish used for calculating the age-1 time series; gray crosses: fish not used for time series calculations (i.e. data outside the months or age classes of interest). Monthly values have been jittered to reduce data overlap 

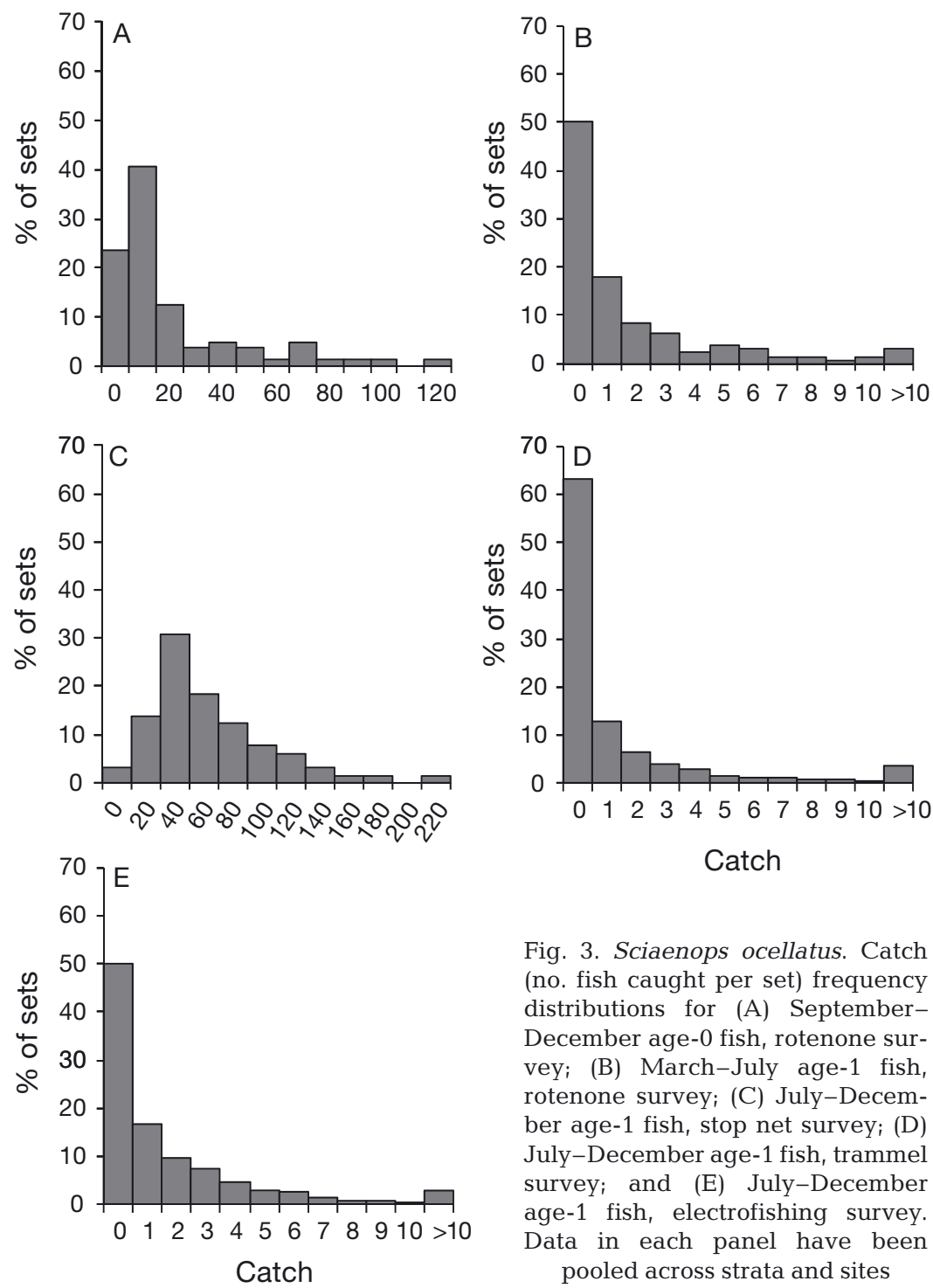
survey; and (E) July-December age-1 fish, electrofishing survey. Data in each panel have been pooled across strata and sites fixed factors in the binomial and generalized linear models. For the trammel survey, tide was also entered (early-, mid- or late-ebb) to control for increasing catch rates as the tide retreated from the intertidal habitat over the course of a sampling day (tide factor: $p \leq 0.006$ in all cases except $p=$ 0.46 in the WB generalized linear model).

To test whether CPUE differed among strata surveyed by a particular gear type, an ANOVA was used with stratum and year class as factors.

Standardizing the juvenile time series: All juvenile CPUE time series were standardized against a 'template' to facilitate comparisons across survey types and sampling strata. The template was generated by combining time series from the AR, CH and LW trammel strata (Fig. 1). Note that the year classes they cover (1990-2007 for LW and $\mathrm{CH}_{\text {; }}$ 1991-2007 for AR) bridge both the rotenone and stop net surveys during the early 1990s, as well as the electrofishing survey from 2000 onwards (Table 1).

To generate the template, the AR, $\mathrm{CH}$ and LW time series were each initially standardized using:

$$
C_{S, Y}^{\prime}=\frac{C_{S, Y}-\bar{C}_{S}}{\sigma_{S}}
$$

where $C^{\prime}{ }_{S, Y}$ is the standardized CPUE for year class $Y$ in stratum $S, C_{S_{1} Y}$ is the unstandardized CPUE value, and $\bar{C}_{S}$, and $\sigma_{S}$ are the mean and standard deviation CPUE in stratum $S$ across

and it was not possible to normalize any of these data. Therefore, the rotenone, trammel and electrofishing time series were all calculated using delta-gamma models (Maunder \& Punt 2004). Briefly, this method splits the catches into 2 separate data sets: a presence/absence data set and a positive catch data set. A binomial model was fit to the presence/absence data to determine the probability of a positive catch, and a generalized linear model was fit to the positive catch data to determine mean catch, assuming a gamma distribution. The product of the 2 model outputs (probability of a positive catch $\times$ mean positive catch) was then used as a measure of CPUE. All delta-gamma models were run using the statistical package $R$ (www.rproject.org). For the rotenone and electrofishing time series, year class and month were entered as the year classes 1991-2007 (i.e. the year classes AR, $\mathrm{CH}$ and LW all had in common). The template was then generated by averaging $C^{\prime}{ }_{S, Y}$ across all 3 time series and re-standardizing with respect to the 1990-2007 year classes, creating a template with a mean and standard deviation of 0 and 1 , respectively.

Each of the 16 juvenile time series was then standardized against the template. To achieve this, a time series was initially standardized with respect to the period $P$, i.e. those year classes it had in common with the template, such that:

$$
C^{\prime}{ }_{S, Y}=\frac{C_{S, Y}-\bar{C}_{S, P}}{\sigma_{S, P}}
$$

where $\bar{C}_{S, P}$ and $\sigma_{S, P}$ are the mean and standard deviation CPUE, respectively, for stratum $S$ during period $P$. 
These values were then standardized against the template, such that:

$$
C^{\prime \prime}{ }_{S, Y}=\left(\sigma_{T, P} C^{\prime}{ }_{S, Y}\right)+\bar{C}_{T, P}
$$

where $C^{\prime \prime}{ }_{S, Y}$ is the template-standardized CPUE for year class $Y$ in stratum $S$, and $\bar{C}_{T, P}$ and $\sigma_{T, P}$ are the template mean and standard deviation, respectively, during period $P$.

Spatial synchrony of juvenile time series: To examine synchrony among the juvenile time series, we used the template-standardized data from the 7 trammel strata and 5 electrofishing strata. Synchrony between a pair of time series was quantified by calculating the Pearson product-moment correlation coefficient $(r)$ for the year classes they had in common (Liebhold et al. 2004). Thus synchrony can potentially range between +1 (in-phase) and -1 (out-of-phase), with 0 representing no synchrony. A 1-sample sign test was used to determine whether the median of all synchrony values differed from zero.

The matrix of $r$ values (66 pairwise correlations among the 12 strata) was compared against the matrix of geographic distances $(D)$ separating each pair of strata, where $D$ is the minimum distance via water between pairs of stratum centroids $( \pm 0.1 \mathrm{~km})$. Centroids were calculated as the mean latitude and longitude of all sites in a stratum, weighted by the number of sets analyzed from each site. If the centroid was on land (some electrofishing strata), it was moved to the nearest water location within the stratum.

Mantel and partial Mantel tests (Mantel 1967) were used to test whether synchrony was related to geographic distance or genetic distance. The tests were performed with zt software (www.jstatsoft.org/v07/i10; Bonnet \& Van de Peer 2002) using synchrony values from only the 2000-2007 year classes to control for temporal coverage bias (NB: most strata had full coverage for these year classes).

The rate at which synchrony decayed with geographic distance was fit using 3 types of models: a linear regression, an exponential decay and a sigmoid decay model. They were fit with TableCurve2D software (www.sigmaplot.com) using synchrony values from all available year classes, weighted by the number of year classes covered.

The geographic distance at which synchrony was predicted to decay to zero $(d)$ was estimated by extrapolating the linear regression, which had synchrony as the dependent variable and geographic distance as the independent variable.

The exponential decay model took the form:

$$
r_{D}=r_{0} \mathrm{e}^{-(D / v)}
$$

where $r_{D}$ is synchrony at geographic distance $D, r_{0}$ is the y-axis intercept (synchrony at $D=0$ ) and $v$ is the exponential decay rate, or e-folding scale (i.e. $D$ when $r_{0}$ is reduced by $\mathrm{e}^{-1}=36.8 \%$ ). Two versions were fit, one with a constraint of $r_{0}=+1$, and another with a relaxed constraint of $-1 \leq r_{0} \leq+1$. The e-folding scale $(v)$ provides a measure of the spatial extent of synchrony, and was compared against values fit for other fish species by Myers et al. (1997).

The sigmoid decay model took the form:

$$
r_{D}=r_{0} \mathrm{e}^{-0.5(D / \sigma)^{2}}
$$

(also following Myers et al. 1997), where $\sigma$ represents the geographic distance at which the fitted curve inflects (also the distance at which $r_{0}$ is reduced by $\mathrm{e}^{-0.5}=60.7 \%$ ).

Akaike's information criterion (AIC) was used for comparing goodness of fit among models, with a lower AIC indicating a better fit (Sakamoto et al. 1986).

Region-wide juvenile time series: A single, regionwide juvenile time series was derived to cover all of the year classes surveyed by the various gear types (1985-2007; Table 1). To do this, 5 survey-specific time series were initially generated, including: the template, as described above (TEMPLATE; using the $\mathrm{AR}, \mathrm{CH}$ and LW trammel strata); an additional trammel net time series for the other (non-template) trammel strata (TRAM_OTH; using the AB, MB, RH and WB strata); a rotenone time series (ROT; using the age-0 and age-1 strata); a stop net time series (STOP; using the 0001 and 0270 strata); and an electrofishing time series (ELEC; using the CO, LE, UA, UC and EW strata). Each survey-specific time series was calculated by taking the mean of the various templatestandardized time series it comprised, and then restandardizing the survey-specific time series against the template, as above.

The TRAM_OTH, ROT, STOP and ELEC time series were each plotted against the TEMPLATE time series to check whether they deviated from it during the year classes they had in common. They were considered to be similar to the TEMPLATE time series if the intercept and slope of their relationship with it did not differ from 0 and 1, respectively (tested using the general linear model function of Minitab 15).

A region-wide time series was generated by averaging across the 5 survey-specific time series and restandardizing against the template. Thus all values are expressed as standard deviations from the 1990-2007 year class mean CPUE.

One issue with the region-wide juvenile time series described above is that no weighting factors were applied to the stratum- or survey-specific time series, which could introduce bias if some were more regionally representative than others (Krebs 1998). Therefore, we ran 10000 Monte Carlo simulations with random weighting factors (ranging from 0 to 1 ) applied to 
each stratum- and survey-specific time series. This enabled us to explore the full range of potential outcomes in our comparisons between juveniles and adults.

Comparison between juveniles and adults. Year class frequency of adult red drum was compared against year class abundance in the region-wide juvenile time series using a Pearson product-moment correlation coefficient. Three sets of comparisons were made. The first used the raw adult data. In the second, an adjustment for adult mortality was made using:

$$
N_{Y, 1}=\frac{N_{Y, a}}{\mathrm{e}^{-M(a-1)}}
$$
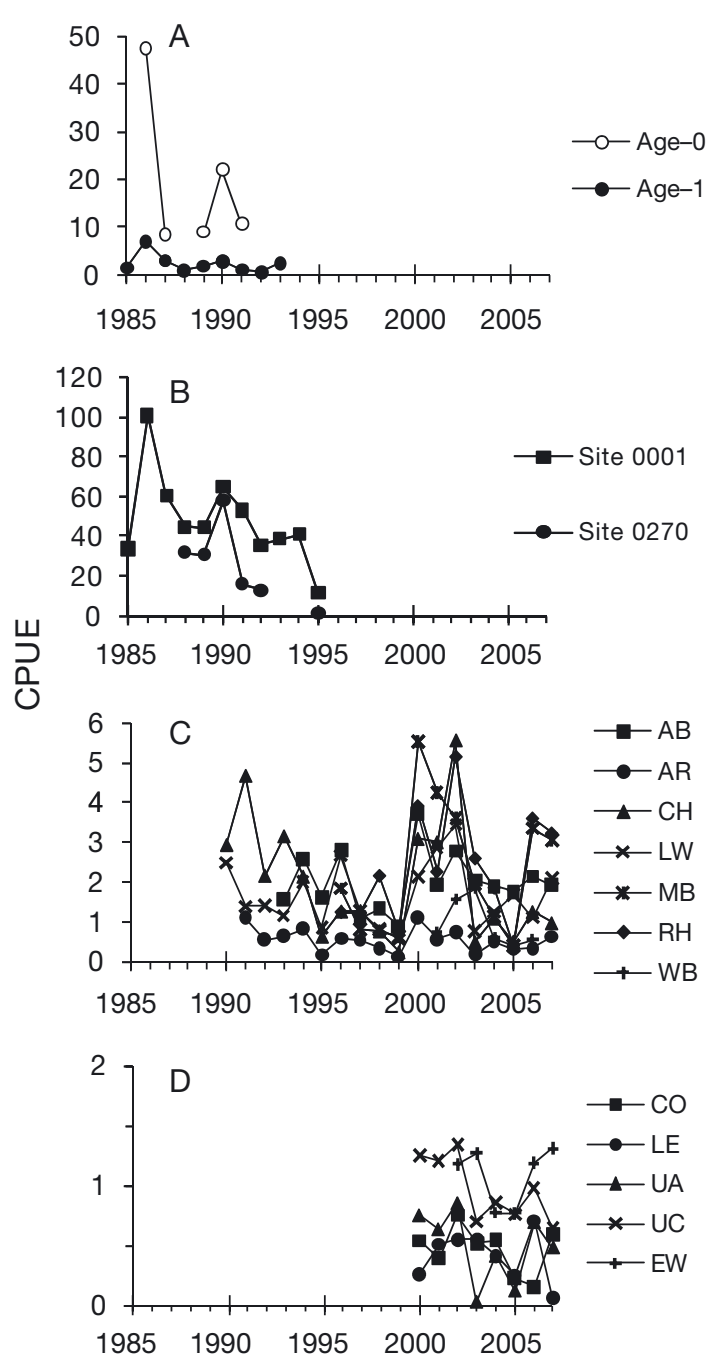

where $N_{Y, 1}$ is the number of adults in year class $Y$ adjusted to age-1, $N_{Y, a}$ is the number of adults observed from year class $Y$ at age- $a$ and $M$ is an instantaneous mortality of 0.075 (a conservative estimate of mortality; SEDAR 2009b). In the third comparison, $M$ was iteratively adjusted so as to maximize the correlation coefficient between the adults and juveniles.

Adult data were initially compared against the region-wide juvenile time series that was calculated without weighting factors. Additional comparisons were made against the Monte Carlo simulated data set $(\times 10000$ time series; see above). The distribution of correlation coefficients derived from the simulations was used to obtain $95 \%$ confidence intervals.
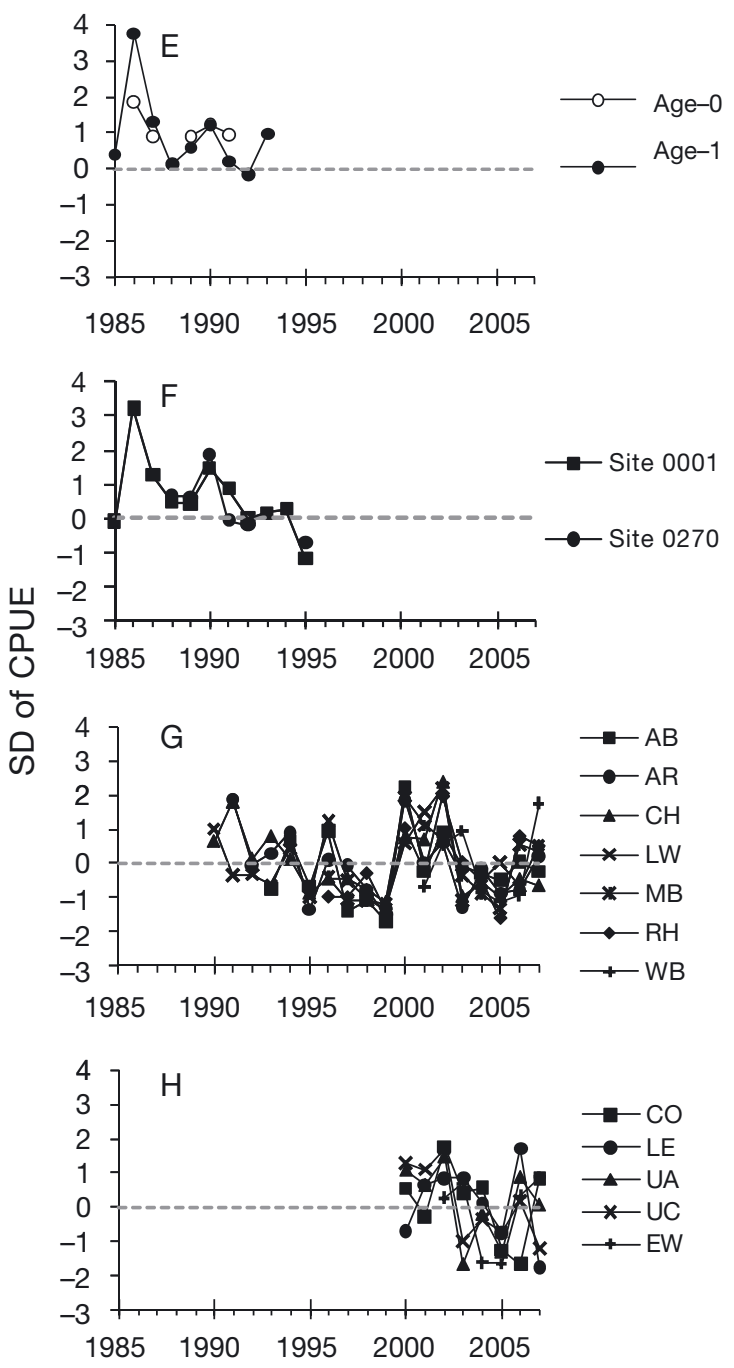

Year class

Fig. 4. Sciaenops ocellatus. Juvenile time series plots from the $(\mathrm{A}, \mathrm{E})$ rotenone, $(\mathrm{B}, \mathrm{F})$ stop net, $(\mathrm{C}, \mathrm{G})$ trammel and $(\mathrm{D}, \mathrm{E})$ electrofishing surveys. (A-D) Catch per unit effort (CPUE); (E-H) standardized against the template (dashed line: template mean for year classes 1990-2007). The rotenone plots show time series of both age-0 and age-1 fish, whereas all other plots show age- 1 time series from different sampling strata. See Fig. 1 for strata locations and definitions 


\section{RESULTS}

\section{Juvenile CPUE time series}

The CPUE time series from the rotenone and stop net surveys revealed peaks in juvenile abundance for the 1986 and 1990 year classes (Fig. 4A,B). In the rotenone survey, age-0 CPUE was higher than age-1 CPUE (on average, 6.4 times higher), but their trends in year class fluctuations were correlated $(r=0.93, p=0.022)$.

Mean CPUE in the trammel net survey differed significantly among strata (ANOVA, $\mathrm{p}<0.0001$ ), with the AR stratum yielding significantly lower catches than all other strata (Tukey's tests, $\mathrm{p} \leq 0.0002$ ) except LW $(p=0.08)$ and WB $(p=0.90)$. WB also had lower catches than $\mathrm{RH}$ ( $\mathrm{p}<0.05)$. In general, the trammel CPUEs declined during the 1990 to 1999 year class period (Fig. 4C). The 2000 and 2002 year classes had prominent peaks in most strata, followed by a gradual decline until the 2006 and 2007 year classes.

Mean CPUE in the electrofishing survey differed significantly among strata (ANOVA, $\mathrm{p}<0.0001$ ), with the EW and UC strata producing higher catches than the CO, LE and UA strata (Tukey's tests, $\mathrm{p} \leq 0.001$ ). The general trends in year class strength were similar to those in the trammel survey (Fig. 4D).

\section{Standardized juvenile time series}

After standardizing all the juvenile time series, clear similarities in their temporal dynamics were evi- dent across strata and survey types (Fig. 4E-H). In general, the rotenone, stop net and trammel time series showed positive correlations among one another, as did the trammel and electrofishing time series.

\section{Synchrony of juvenile populations}

Synchrony of juvenile populations varied between -0.39 and +0.91 . Most values (59 of the 66 pairwise comparisons) were positive, and the median value of +0.52 was significantly greater than zero (1-sample sign test, $\mathrm{p}<0.0001)$.

Synchrony declined significantly with geographic distance (Mantel test, $\mathrm{r}=-0.512, \mathrm{p}=0.008$ ). According to the linear regression model, zero synchrony was predicted at a distance of $284 \mathrm{~km}$. The e-folding scale of the exponential model was $117 \mathrm{~km}$ when $r_{0}$ was constrained at +1 and $204 \mathrm{~km}$ when the constraint was relaxed. Inflection of the sigmoidal model occurred at a distance of $112 \mathrm{~km}$. The Akaike's information criterion (AIC) values of the different models were very similar, with the sigmoidal model providing a marginally better fit that the others (Table 2).

One notable feature of all the models was that residuals of the LE stratum lay below any of the fitted lines (1-sample $t$-test, $\mathrm{p}<0.0001$ in all cases; Fig. 5). Omitting the LE data resulted in models that had slightly slower rates of decay in synchrony (Table 2), with the adjusted linear model predicting zero synchrony at a distance of $362 \mathrm{~km}$.

Table 2. Sciaenops ocellatus. Model parameters describing the decay in synchrony of juvenile red drum populations with respect to geographic distance, including weighted fits for the linear regression, exponential decay and sigmoid decay models. Model parameters include the $y$-axis intercept $\left(r_{0}\right)$, the e-folding scale of the exponential models $(v)$ and the inflection point of the sigmoid model $(\sigma)$. The models were fitted with all available data, and also with the LE stratum (Edisto River) data omitted (due to low residuals). AIC: Akaike's information criterion. Fitted curves are shown in Fig. 5

\begin{tabular}{|c|c|c|c|c|c|c|}
\hline Data & Model & Constraint & Parameter & Fitted value $( \pm \mathrm{SE})$ & Adj. $\mathrm{R}^{2}$ & AIC \\
\hline \multirow[t]{4}{*}{ All } & Linear & $-1 \leq r_{0} \leq+1$ & $\begin{array}{c}r_{0} \\
\text { Slope }\end{array}$ & $\begin{array}{c}0.704(0.069) \\
-0.00252(0.0006)\end{array}$ & 0.170 & 163.3 \\
\hline & Exponential & $r_{0}=+1$ & $\begin{array}{c}r_{0} \\
V\end{array}$ & $\begin{array}{c}1 \\
109.3(12.3)\end{array}$ & 0.101 & 167.6 \\
\hline & Exponential & $-1 \leq r_{0} \leq+1$ & $\begin{array}{c}r_{0} \\
V\end{array}$ & $\begin{array}{c}0.754(0.091) \\
170.6(46.1)\end{array}$ & 0.172 & 163.1 \\
\hline & Sigmoid & $-1 \leq r_{0} \leq+1$ & $\begin{array}{c}r_{0} \\
\sigma\end{array}$ & $\begin{array}{c}0.657(0.061) \\
112.0(16.1)\end{array}$ & 0.178 & 162.7 \\
\hline \multirow[t]{4}{*}{ LE omitted } & Linear & $-1 \leq r_{0} \leq+1$ & $\begin{array}{c}r_{0} \\
\text { Slope }\end{array}$ & $\begin{array}{c}0.746(0.055) \\
-0.00236(0.0006)\end{array}$ & 0.222 & 105.7 \\
\hline & Exponential & $r_{0}=+1$ & $\begin{array}{c}r_{0} \\
V\end{array}$ & $\begin{array}{c}1 \\
136.0(13.5)\end{array}$ & 0.109 & 112.2 \\
\hline & Exponential & $-1 \leq r_{0} \leq+1$ & $\begin{array}{c}r_{0} \\
V\end{array}$ & $\begin{array}{c}0.781(0.068) \\
220.9(54.7)\end{array}$ & 0.227 & 105.4 \\
\hline & Sigmoid & $-1 \leq r_{0} \leq+1$ & $\begin{array}{c}r_{0} \\
\sigma\end{array}$ & $\begin{array}{c}0.694(0.046) \\
131.3(17.3)\end{array}$ & 0.220 & 105.8 \\
\hline
\end{tabular}




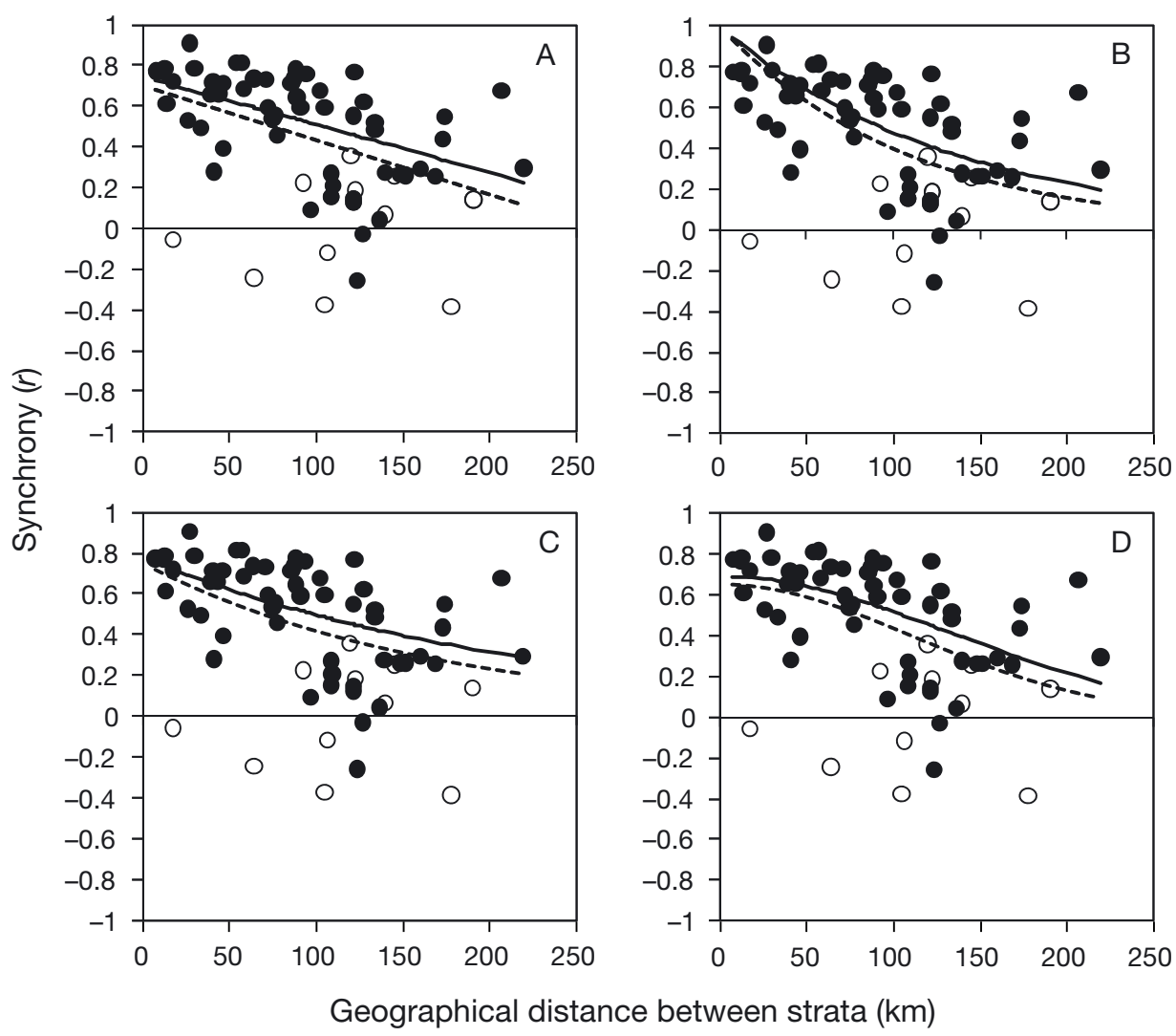

Fig. 5. Sciaenops ocellatus. Synchrony $(r)$ of age-1 red drum against geographic distance. Each point represents a pairwise comparison between 2 strata. Curves were fit using (A) a linear regression, (B) an exponential model with $r_{0}=+1,(\mathrm{C})$ an exponential model with the constraint on $r_{0}$ relaxed and (D) a sigmoid model. Dashed lines show models fitted to all the data; solid lines show models fit with the LE data (empty circles) omitted. Model parameters are in Table 2

\section{Genetic distances}

Mean $( \pm \mathrm{SD})$ genetic distances between pairs of strata for the 2004, 2005 and 2007 year classes were: $0.028 \pm$ $0.010,0.084 \pm 0.051$ and $0.047 \pm 0.018$, respectively, using the Nei method; $0.012 \pm 0.003,0.030 \pm 0.014$ and $0.016 \pm 0.001$, respectively, using the C-S method; and $0.010 \pm 0.003,0.033 \pm 0.020$ and $0.016 \pm 0.001$, respectively, using the RWC method. The 2005 year class values were significantly greater than the other year classes (ANOVA followed by Tukey's tests, $p \leq 0.001$, regardless of genetic distance method). The $2004 \mathrm{C}-\mathrm{S}$ values increased significantly with geographic distance (Mantel test, $r=0.66, p=0.006$; Fig. 6), but the effect was only marginal with the Nei and RWC values ( $\mathrm{r}=$ $0.40, p=0.07$ in both instances). No significant effect of geographic distance was detected with any of the 2005 and 2007 genetic measures ( $\mathrm{p} \geq 0.35)$.

Synchrony of juvenile time series was not related to any measure of genetic distance, either directly (Mantel tests, $p \geq 0.25$ ) or after controlling for the effect of geographic distance on synchrony (partial Mantel tests, $\mathrm{p} \geq 0.22$ ).

\section{Region-wide juvenile time series}

The region-wide juvenile time series showed positive correlations with all 16 of the individual juvenile time series. Strong positive relationships existed between the survey-specificjuveniletime series and the template, with none of the relationships differing significantly from a slope of 1 ( $p \geq 0.62$ ) that passed through the origin ( $p \geq 0.18$; Fig. 7A). There was a region-wide decline in juvenile abundance during the 1990-1999year classes, with a transientincrease during the 2000-2003 year classes (Fig. 7B).

\section{Comparison between juvenile and adult year classes}

The oldest captured adult red drum belonged to the 1969 year class (age-38 when caught), whereas the youngest belonged to the 2004 year class (age-3). Among the adults caught, no significant difference was found between the year class composition of fish collected in 2007 versus $2008\left(\chi^{2}=3.19\right.$, df $\left.=5, p=0.67\right)$, nor between samples from the northern versus southern parts of South Carolina $\left(\chi^{2}=1.554, \mathrm{df}=7, \mathrm{p}=0.98\right)$. 


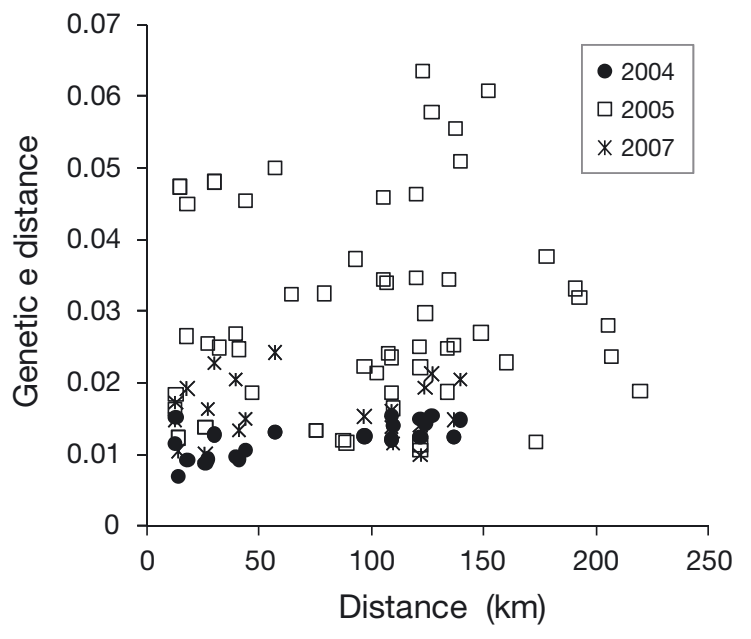

Fig. 6. Sciaenops ocellatus. Genetic distance (C-S chord measure) plotted against geographic distance for wild-spawned age-1 red drum from the 2004, 2005 and 2007 year classes. Each point represents a pairwise comparison between 2 survey strata. Values for 2004 increased significantly with geographic distance, whereas 2005 and 2007 values did not
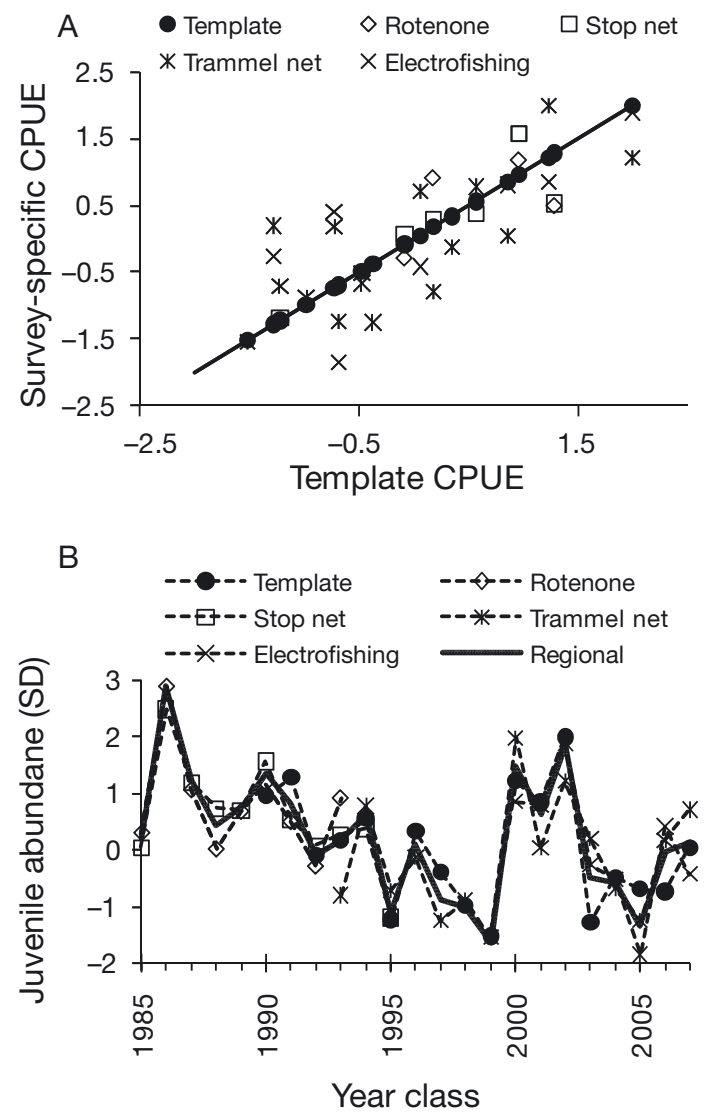

Fig. 7. Sciaenops ocellatus. Region-wide time series. (A) Scatter plots of survey-specific juvenile catch per unit effort (CPUE) indices against the template. (B) Temporal plots of the region-wide and survey-specific juvenile time series. Data are expressed as standard deviations from the 1990-2007 mean

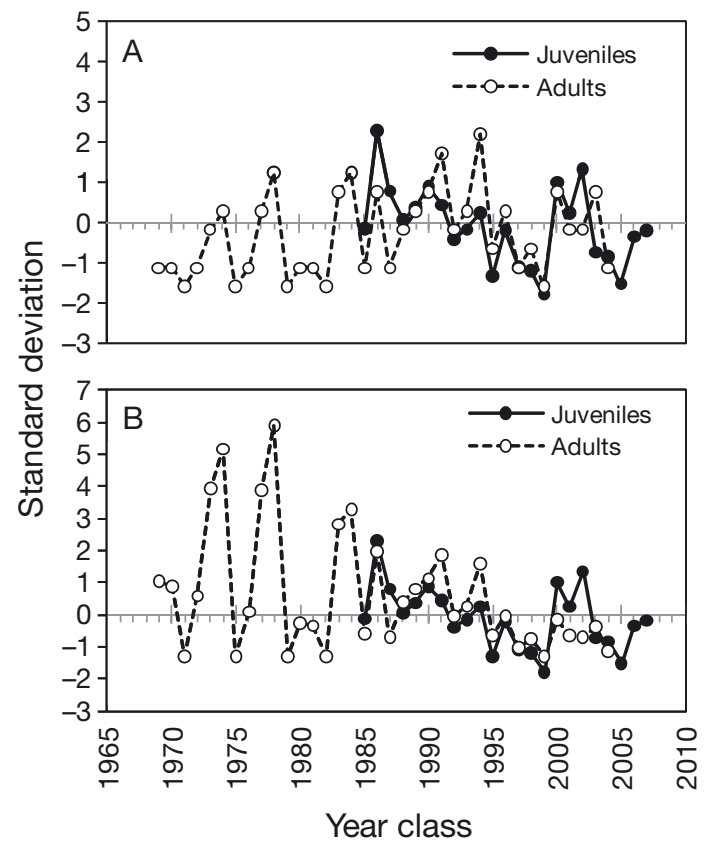

Fig. 8. Sciaenops ocellatus. Comparisons between year class composition of adult red drum and the region-wide juvenile time series in South Carolina. All data are expressed as standard deviations from the 1985-2004 mean (period shared by the juvenile and adult time series). (A) Adult year class composition with no adjustment for mortality, (B) adult year class composition assuming mortality $=0.075$

Of the 101 otoliths examined, 67 belonged to the 1985-2007 year classes (i.e. the period covered by the region-wide juvenile time series). The adult year class composition showed positive relationships with 13 of the 16 individual juvenile time series, and was significantly correlated with the region-wide juvenile time series (Pearson correlation, $r=0.51, p=0.026$; Fig. 8A). The correlation coefficient was very similar to the mean value of 0.50 (range $=0.35$ to $0.64,95 \% \mathrm{CI}=0.43$ to 0.57 ) obtained from the Monte Carlo simulations.

Accounting for adult mortality strengthened the correlation with the region-wide juvenile time series $(\mathrm{r}=$ $0.62, p=0.006$ when mortality $=0.075$; for Monte Carlo simulations, mean $\mathrm{r}=0.61$, range $=0.37$ to $0.72,95 \%$ $\mathrm{CI}=0.50$ to $0.69 ;$ Fig. $8 \mathrm{~B}$ ). The correlation between adults and juveniles was optimized at a mortality of 0.21 , although this led to an order of magnitude inflation of adult year classes prior to 1985 and an apparent underrepresentation of more recent year classes.

\section{DISCUSSION}

Our analyses show that annual fluctuations in juvenile red drum abundance are correlated (i.e. synchronized) among estuarine habitats along the coastline of 
South Carolina. Population synchrony declined by more than $60 \%$ over a geographic distance of 109 to $221 \mathrm{~km}$ (depending on model assumptions), whereas genetic distance increased only slightly or not at all (depending on year class). Catches in all 4 juvenile surveys showed similar annual fluctuations in their standardized measures of juvenile abundance, which enabled us to generate a region-wide recruitment time series spanning a 23 yr period by concatenating across surveys. These data correlated with the year class composition of the present-day adult population, which was sampled by a separate survey of deeper adult habitats.

\section{Synchrony}

According to the linear model we used, synchrony in juvenile red drum abundance decays to zero at $\sim 284 \mathrm{~km}$ along the South Carolina coastline. However, this is probably an underestimate because rates of decay in synchrony typically become less steep as geographic distance increases (Sutcliffe et al. 1996, Myers et al. 1997). Our exponential decay models, which account for these rate changes, had e-folding scales (decay in synchrony by $\mathrm{e}^{-1}$ ) of 109 to $171 \mathrm{~km}$ when all of the strata were considered (depending on the model constraint). The single parameter exponential model had a higher AIC value (suggesting a poorer fit), but it accommodates the fact that pairwise estimates of synchrony are increasingly likely to be underestimated at small geographical distances because their correlations can only be 1 or less (the error can never exceed 1). The sigmoid model, which accounts for an apparent 'shoulder' in the response at small distances, had an inflection point at $112 \mathrm{~km}$ (Table 2, Fig. 5) and its equivalent decay of $\mathrm{e}^{-1}$ equates to $158 \mathrm{~km}$ (i.e. similar to the e-folding scale of the exponential models).

Synchrony values for the LE stratum lay significantly below any of the fitted models (Fig. 5), but the reason for this is unknown. One possibility is that LE has particular habitat conditions that differ from the other survey strata. Alternatively, the comparatively short duration of the time series may make it sensitive to just 1 or 2 unusual year classes (e.g. 2007).

Our estimates of the spatial extent of synchrony are in general agreement with the values found by Myers et al. (1997). They estimated e-folding scales of $\sim 500 \mathrm{~km}$ for marine species, $\sim 50 \mathrm{~km}$ for freshwater species and intermediate distances for anadromous species, probably because of differences in habitat homogeneity and dispersal potential. The extent of synchrony for South Carolina juvenile red drum was in the intermediate range, which fits with their estuarine and nearshore lifestyle.
The maximum distance between strata that were examined in our data set was $219 \mathrm{~km}$, whereas the full species range for red drum extends more than $3000 \mathrm{~km}$ along the western coasts of the North Atlantic and Gulf of Mexico. Two previous studies have examined correlations among juvenile red drum populations. One was in Texas (Scharf 2000) and the other was in North Carolina (Bacheler et al. 2008), and both studies found that the strength of the correlations decayed with distance, although their rates of decay were not specified. Bacheler et al. (2008) additionally compared their North Carolina juvenile time series with data from Florida and Texas, but found no significant correlations across this much broader geographic scale. Nevertheless, South Carolina (Fig. 4) and the west coast of Florida (Murphy \& Crabtree 2001) both seem to have experienced a strong year class in 1986, and South Carolina and Texas (Scharf 2000) both seem to have experienced a strong year class in 1990. Clearly, a more detailed analysis of synchrony across the full extent of the species' range is warranted before more general conclusions can be drawn, but it is worth noting that sampling range can influence the extent of spatial relationships that are detected (Levin 1992, Dungan et al. 2002), and that synchrony itself may change over time (Ranta et al. 1998).

Simulation models (Molofsky 1994, Ranta et al. 1998) and field studies on a wide variety of organisms (Liebhold et al. 2004) both indicate that dispersal is an important source of synchronization. In red drum, dispersal during any of its life stages could potentially affect the spatial synchrony of age-1 fish (i.e. the age we examined). For example, dispersal of juveniles across estuaries would spatially synchronize their population dynamics per se, while dispersal of adults would spatially homogenize the supply of eggs across different estuaries. In addition, prevailing water currents during the egg and larval stages may disperse them from a single source across multiple nursery areas, again promoting local synchrony among habitats.

Tagging of juvenile red drum in South Carolina estuaries shows that individuals can disperse over distances of at least $230 \mathrm{~km}$ from their initial tagging location, although this seems to be comparatively rare since more than $95 \%$ of tags returned by recreational anglers have been caught within $15 \mathrm{~km}$ of the fish's tagging location $(\mathrm{N}=13332$ returns since 1986; SCDNR unpubl. data). Similarly, red drum tagged in North Carolina rarely move into South Carolina waters (Bacheler et al. 2009). Genetic monitoring of red drum stocked at age-0 in South Carolina estuaries has revealed that most fish remain in the area of release for 2 or more years, although a small proportion do disperse distances of at least $35 \mathrm{~km}$ (Collins et al. 2002, Jenkins et al. 2004). 


\section{Genetics}

Our microsatellite studies indicate that genetic segregation of juvenile red drum along the South Carolina coastline appears to be weak, but variable from year to year. The 2005 and 2007 year classes of red drum showed no evidence of increasing in genetic distance with geographic distance. However, in the 2004 year class, a significant effect was detected using the C-S genetic measure, and marginally significant effects were detected using the Nei and RWC measures. Studies by Takezaki \& Nei $(1996,2008)$ indicate that the $\mathrm{C}-\mathrm{S}$ method is probably the most appropriate of the 3 measures we used, adding weight to our findings. It is notable that the maximum geographic distance between strata that was tested was only $139 \mathrm{~km}$ with the 2004 and 2007 genetic data sets (compared with $219 \mathrm{~km}$ for the 2005 year class), although the sample size for the 2004 year class ( $\mathrm{n}=461$ fish) was larger than the $2005(n=330)$ and $2007(n=324)$ year classes. The larger 2004 sample size may have increased the likelihood of detecting a relationship between genetic distance and geographic distance, despite the smaller geographic coverage. Alternatively, the different genetic responses among year classes may have been caused by annual differences in the dispersal of eggs and larvae, which could vary depending on annual weather and ocean conditions during the spawning period. Previous work on genetic segregation in red drum found genetic neighborhood distances of 500 to $900 \mathrm{~km}$ (Gold et al. 1999, Gold \& Turner 2002), with an apparent linear (stepping stone) pattern of dispersal (Gold et al. 2001, Chapman et al. 2002). Taken together, these data suggest that genetic structuring of juvenile red drum in South Carolina operates across a broader spatial scale than their population synchrony, since genetic distance was less affected by geographic distance than was synchrony.

\section{Region-wide juvenile time series}

The synchrony and genetic relatedness of juvenile red drum among strata in South Carolina imply that the region-wide juvenile time series is a meaningful measure of year class strength. One potential source of bias in this time series is that different numbers of strata contributed towards each year class's regionwide index. However, the various survey programs conducted by SCDNR were all initiated in the Charleston Harbor area and then expanded northwards and southwards as new strata were added. Since Charleston Harbor is located in the middle portion of South Carolina, its temporal dynamics in juvenile abundance probably provides a reasonable estimate of region-wide dynamics, and minimizes disproportional influences of strata at the northern and southern margins of the area covered.

In order to maximize the time period covered by our region-wide time series, it was necessary to use data collected by 4 different gear types, which complicated the comparison of early periods (1980s) with later ones. Fortunately, 3 of the strata $(\mathrm{CH}, \mathrm{AR}$ and LW) sampled by the trammel survey overlapped with all of the other surveys (Table 1), which enabled us to standardize all the time series against a common template. However, some time series had more year classes overlapping the template than others, and time series with a shorter overlap might be less reliable because they were standardized with respect to a smaller subset of the template data. In addition, the rotenone and stop net surveys took place at a smaller number of fixed or non-randomly selected sampling sites than the later surveys. Nevertheless, these early time series demonstrated similar trends to one another, as well as with the template.

The limited amount of data we examined for age-0 red drum (rotenone survey) showed that their year class fluctuations correlated with the age-1 patterns that were observed $1 \mathrm{yr}$ later in both the rotenone (Fig. 4E) and stop net (Fig. 4F) surveys. While these observations span only 5 year classes, they suggest that year class strength is primarily governed by conditions very early in life, before the age-0 fish were sampled. Bacheler et al. (2008) came to a similar conclusion for North Carolina red drum, based on relationships between age-0 abundance and harvest records $2 \mathrm{yr}$ later of the same year classes. Conversely, in Texas, Scharf (2000) found poor relationships between the initial catch rates of age-0 red drum and their catch rates several months later, implying that post-settlement mortality was an important modifier of year class strength in that area.

\section{Comparison between juveniles and adults}

Our region-wide time series of juvenile year class abundance was significantly correlated with the year class composition of the present-day adult red drum population in South Carolina, even though only a relatively small number of adult otoliths were available (67 of the 101 otoliths belonged to year classes covered by the juvenile time series). The relationship was robust to adjustments in weighting factors used for generating the region-wide juvenile time series, as shown by the Monte Carlo simulations.

The correlation between juvenile and adult year classes was strengthened by adjusting for adult mortality. However, attempts to optimize this relationship 
by iterative adjustment of mortality led to unrealistically high frequencies of older fish and underrepresentation of younger fish among the adults. Several factors probably contributed towards this. Firstly, the low number of adult otoliths meant that the results were highly sensitive to slight adjustments in year class frequencies. In addition, the assumption of constant mortality is over-simplistic, since mortality likely varies with both age and year class. The latter of these is affected by factors such as fishing effort and harvest regulations (SEDAR 2009a), which varied over time. In Florida, Murphy \& Crabtree (2001) found that juvenile red drum recruitment and adult year class composition correlated with one another. However, the relationship they detected existed only during a period of year classes that experienced low fishing mortality, presumably because very few fish survived until adulthood during periods of high exploitation.

Another potential source of bias in our estimates of adult year class composition is that some juveniles remain within estuaries longer than others before they move offshore to join the adults (Murphy \& Crabtree 2001), so the youngest age classes captured in the long-line survey are probably underrepresented. Furthermore, long-line sampling of the adults may incur size (and therefore age) selectivity, but the selectivity of the long-line gear has not been quantified.

\section{Implications}

Spatial synchrony affects population stability and resilience, which can have important ecological and economic consequences for fisheries (Schindler et al. 2010). Our study detected synchrony in juvenile red drum populations along the South Carolina coastline (covering a scale of tens to hundreds of kilometers), indicating that a poor year class in one area is likely to be reflected elsewhere in the state. However, exceptions to the rule were detected and considerable variation occurred around the curves fitted to the synchrony data (e.g. 7 of our 66 pairwise comparisons had negative correlations; Fig. 5). The source of this variation is unknown, but it indicates that preserving a diverse network of juvenile habitat along the coastline would be beneficial for fisheries by buffering, to some degree, against boom and bust cycles (Kerr et al. 2010, Schindler et al. 2010). Future property development along the shoreline has the potential to erode the extent and diversity of juvenile habitat, which could alter synchrony and destabilize red drum population dynamics (Moore et al. 2010).

Future studies examining synchrony of red drum across a broader scale would be of interest to individual state agencies responsible for setting management regulations. At present, it is unclear to what degree current stock assessments (which cover multi-state management units) reflect the population dynamics within smaller (state-level) sections of coastline. It may be that localized population trends become masked by the larger-scale dynamics of the management unit.

Across a much broader scale (multiple management units), Bacheler et al. (2008) found no evidence of synchrony among juvenile red drum from North Carolina, Florida and Texas. A useful extension of their work, and ours, would be to incorporate additional data across the entire range of red drum using a fine spatial resolution to fill in the gaps. Such analyses could be useful for identifying the environmental factors that drive population changes (Noakes \& Beamish 2009).

Acknowledgements. We thank the many workers, students and volunteers who have participated in the SCDNR Inshore Fishery surveys. We also thank G. Nelson, who provided sources of R code, and J. Boynton, who provided GIS mapping expertise (Fig. 1). The research was supported by grant nos. F-85-R4 and F-77-6 of the Federal Aid in Sport Fish Restoration program, and the state of South Carolina. This is publication no. 669 from the Marine Resources Division, South Carolina Department of Natural Resources.

\section{LITERATURE CITED}

Allen DM, Ogburn-Matthews V, Buck T, Smith EM (2008) Mesozooplankton responses to climate change and variability in a southeastern US estuary (1981-2003). J Coast Res 55:95-110

> Bacheler NM, Paramore LM, Buckel JA, Scharf FS (2008) Recruitment of juvenile red drum in North Carolina: spatiotemporal patterns of year-class strength and validation of a seine survey. N Am J Fish Manag 28: 1086-1098

Bacheler NM, Paramore LM, Burdick SM, Buckel JA, Hightower JE (2009) Variation in movement patterns of red drum (Sciaenops ocellatus) inferred from conventional tagging and ultrasonic telemetry. Fish Bull 107:405-419

Bailey KM, Houde ED (1989) Predation on eggs and larvae of marine fishes and the recruitment problem. Adv Mar Biol 25:1-67

Bjørnstad ON, Ims RA, Lambin X (1999) Spatial population dynamics: analyzing patterns and processes of population synchrony. Trends Ecol Evol 14:427-432

Bonnet E, Van de Peer Y (2002) zt: a software tool for simple and partial Mantel tests. J Stat Softw 7:1-12

Cavalli-Sforza LL, Edwards AWF (1967) Phylogenetic analysis: models and estimation procedures. Evolution 21: 550-570

Chapman RW, Ball AO, Mash LR (2002) Spatial homogeneity and temporal heterogeneity of red drum (Sciaenops ocellatus) microsatellites: effective population sizes and management implications. Mar Biotechnol 4:589-603

Collins MR, Smith TIJ, Jenkins WE, Denson MR (2002) Small marine reserves may increase escapement of red drum. Fisheries 27:20-24

Cushing DH (1985) Climate and fisheries. Academic Press, London

Danzmann RG (1997) PROBMAX: a computer program for 
assigning unknown parentage in pedigree analysis from known genotypic pools of parents and progeny. Heredity 88:333

> Dungan JL, Perry JN, Dale MRT, Legendre P and others (2002) A balanced view of scale in spatial statistical analysis. Ecography 25:626-640

Gold JR, Turner TF (2002) Population structure of red drum (Sciaenops ocellatus) in the northern Gulf of Mexico, as inferred from variation in nuclear-encoded microsatellites. Mar Biol 140:249-265

Gold JR, Richardson LR, Turner TF (1999) Temporal stability and spatial divergence of mitochondrial DNA haplotype frequencies in red drum (Sciaenops ocellatus) from coastal regions of the western Atlantic Ocean and Gulf of Mexico. Mar Biol 133:593-602

> Gold JR, Burridge CP, Turner TF (2001) A modified steppingstone model of population structure in red drum, Sciaenops ocellatus (Sciaenidae), from the northern Gulf of Mexico. Genetica 111:305-317

> Heino M, Kaitala V, Ranta E, Lindstrom J (1997) Synchronous dynamics and rates of extinction in spatially structured populations. Proc R Soc Lond B 264:481-486

Hjort J (1914) Fluctuations in the great fisheries of northern Europe viewed in the light of biological research. Rapp p-v Reun Cons Perm Int Explor Mer 20:1-228

Hudson PJ, Cattadori IM (1999) The Moran effect: a cause of population synchrony. Trends Ecol Evol 14:1-2

Jenkins WE, Denson MR, Bridgham CB, Collins MR, Smith TIJ (2004) Year-class component, growth, and movement of juvenile red drum stocked seasonally in a South Carolina estuary. N Am J Fish Manag 24:636-647

Kerr LA, Cadrin SX, Secor DH (2010) The role of spatial dynamics in the stability, resilience, and productivity of an estuarine fish population. Ecol Appl 20:497-507

Kimura M, Crow JF (1964) The number of alleles that can be maintained in a finite population. Genetics 49:725-738

Krebs JK (1998) Ecological methodology, 2nd edn. Addison Wesley Longman, New York, NY

Levin SA (1992) The problem of pattern and scale in ecology. Ecology 73:1943-1967

Liebhold A, Koenig WD, Bjørnstad OT (2004) Spatial synchrony in population dynamics. Annu Rev Ecol Syst 35: 467-490

Lux FE, Mahoney JV (1969) First record of the channel bass, Sciaenops ocellata (Linnaeus), in the Gulf of Maine. Copeia 1969:632-633

Mantel N (1967) The detection of disease clustering and a generalized regression approach. Cancer Res 27:209-220

Maunder MN, Punt AE (2004) Standardizing catch and effort data: a review of recent approaches. Fish Res 70: 141-159

Mercer LP (1984) A biological and fisheries profile of red drum, Sciaenops ocellatus. Special Science Report 41. North Carolina Division of Marine Fisheries, Morehead City, NC

Molofsky J (1994) Population dynamics and pattern formation in theoretical populations. Ecology 75:30-39

Moore JW, McClure M, Rogers LA, Schindler DE (2010) Synchronization and portfolio performance of threatened salmon. Conserv Lett doi:10.1111/j.1755-263X.2010. 00119.x

- Moran PAP (1953a) The statistical analysis of the Canadian lynx cycle. I. Structure and prediction. Aust J Zool 1: 163-173

> Moran PAP (1953b) The statistical analysis of the Canadian lynx cycle. II. Synchronization and meteorology. Aust J Zool 1:291-298
Murphy MD, Crabtree RE (2001) Changes in the age structure of nearshore adult red drum off west-central Florida related to recruitment and fishing mortality. N Am J Fish Manag 21:671-678

> Myers RA, Mertz G, Bridson J (1997) Spatial scales of interannual recruitment variations of marine, anadromous, and freshwater fish. Can J Fish Aquat Sci 54:1400-1407

Nei M (1972) Genetic distance between populations. Am Nat 106:283-292

Noakes DL, Beamish RJ (2009) Synchrony of marine catches and climate ocean regime shifts in the North Pacific Ocean. Mar Coast Fish 1:155-168

Pearson JC (1929) Natural history and conservation of redfish and other commercial sciaenids on the Texas coast. Bull US Bur Fish 44:129-214

> Peters KM, McMichael RH Jr (1987) Early life history of the red drum, Sciaenops ocellatus (Pisces: Sciaenidae), in Tampa Bay, Florida. Estuaries 10:92-107

Phelps QE, Graeb BDS, Willis DW (2008) Influence of the Moran effect on spatiotemporal synchrony in common carp recruitment. Trans Am Fish Soc 137:1701-1708

$>$ Ranta E, Kaitala V, Lindstrom J, Linden H (1995) Synchrony in population dynamics. Proc Biol Sci 262:113-118

Ranta E, Kaitala V, Lindstrom J, Helle E (1997) The Moran effect and synchrony in population dynamics. Oikos 78 : 136-142

> Ranta E, Kaitala V, Lundberg P (1998) Population variability in space and time: the dynamics of synchronous population fluctuations. Oikos 83:376-382

- Reynolds J, Weir BS, Cockerham CC (1983) Estimation of the coancestry coefficient: basis for a short-term genetic distance. Genetics 105:767-779

Robbins SN, Darden TL, Ball AO, Denson MR (2008) Genetic parentage analysis of red drum in South Carolina and the use of genotypic data from archived otoliths. N Am J Fish Manag 28:1796-1801

Ross JL, Stevens TM, Vaughan DS (1995) Age, growth, mortality, and reproductive biology of red drums in North Carolina waters. Trans Am Fish Soc 124:37-54

Royama T (1992) Analytical population dynamics. SpringerVerlag, New York

Sakamoto Y, Ishiguro M, Kitagawa G (1986) Akaike information criterion statistics. KTK Scientific Publishers, Tokyo

Scharf FS (2000) Patterns in abundance, growth, and mortality of juvenile red drum across estuaries on the Texas coast with implications for recruitment and stock enhancement. Trans Am Fish Soc 129:1207-1222

Schindler DE, Hilborn R, Chasco B, Boatright CP, Quinn TP, Rogers LA, Webster MS (2010) Population diversity and the portfolio effect in an exploited species. Nature 465: 609-612

SEDAR (Southeast Data Assessment and Review) (2009a) Atlantic states red drum management overview. Report SEDAR18-DW03. South Atlantic Fishery Management Council, North Charleston, SC, available at www.sefsc. noaa.gov/sedar/

SEDAR (Southeast Data Assessment and Review) (2009b) SEDAR 18 stock assessment report, Atlantic red drum. South Atlantic Fishery Management Council, North Charleston, SC, available at www.sefsc.noaa.gov/sedar/

Smith TIJ, Jenkins WE, Denson MR (1997) Overview of an experimental stock enhancement program for red drum in South Carolina. Bull Natl Res Inst Aquac (Suppl) 3: 109-115

Stenseth NC, Mysterud A, Ottersen G, Hurrell JW, Chan KS, Lima M (2002) Ecological effects of climate fluctuations. Science 297:1292-1296 
Stunz GW, Minello TJ, Levin PS (2002) A comparison of early juvenile red drum densities among various habitat types in Galveston Bay, Texas. Estuaries 25:76-85

Sutcliffe OL, Thomas CD, Moss D (1996) Spatial synchrony and asynchrony in butterfly population dynamics. J Anim Ecol 65:85-95

Takezaki N, Nei M (1996) Genetic distances and reconstruction of phylogenetic trees from microsatellite DNA. Genetics 144:389-399

Takezaki N, Nei M (2008) Empirical test of the reliability of phylogenetic trees constructed with microsatellite DNA. Genetics 178:385-392

Editorial responsibility: Matthias Seaman,

Oldendorf/Luhe, Germany
Wenner CA (2000) Contributions to the biology of red drum, Sciaenops ocellatus, in South Carolina. Final report NA47FM0143. National Marine Fisheries Service, St. Petersburg, FL

Wenner CA, Roumillat WA, Moran JE, Maddox MB, Daniel LB, Smith JW (1990) Investigations of the life history and population dynamics of marine recreational fishes in South Carolina. Marine Resources Research Institute, South Carolina Department of Natural Resources, Charleston, SC

Zar JH (1996) Biostatistical analysis. 3rd edn. Prentice Hall, Upper Saddle River, NJ

Submitted: March 20, 2010; Accepted: June 22, 2010

Proofs received from author(s): September 2, 2010 